\title{
ACAROFAUNA DA CAFEICULTURA DE CERRADO EM PATROCÍNIO, MINAS GERAIS
}

\author{
Acarofauna of cerrado's coffee crops in Patrocínio, Minas Gerais
}

\author{
Sheila Spongoski ${ }^{1}$, Paulo Rebelles Reis ${ }^{2}$, Maurício Sérgio Zacarias ${ }^{3}$
}

\section{RESUMO}

A cultura do cafeeiro (Coffea arabica L.) na região de cerrado do Estado de Minas Gerais, mais especificamente no Alto Paranaíba, está se desenvolvendo com muito sucesso. As doenças e pragas vêm causando redução na produtividade e na qualidade do café produzido. Os ácaros fitófagos fazem parte deste problema, pois causam danos econômicos. Sendo assim, este trabalho teve como objetivo o levantamento da acarofauna em cafeeiros daquela região. Foram feitas quatro amostragens de folhas, ramos e frutos, sendo duas no período das águas e duas no período de seca em 2002 e 2003. Foram identificadas três famílias de ácaros fitófagos, quatro de ácaros predadores e quatro de ácaros generalistas. As espécies de ácaros encontradas foram: Brevipalpus phoenicis (Geijskes, 1939) (Tenuipalpidae); Oligonychus sp. (Tetranychidae); Tarsonemus confusus Ewing, 1939, Fungitarsonemus sp., Daidalotarsonemus sp., Phytonemus sp. (Tarsonemidae); Lorrya formosa Cooreman, 1958, Lorrya sp. (Tydeidae); Parapronematus acaciae Baker, 1965 (Iolinidae); Euseius concordis (Chant, 1959), Euseius citrifolius Denmark e Muma, 1970, Amblyseius herbicolus (Chant, 1959) (Phytoseiidae); Asca sp. (Ascidae); Bdella sp. (Bdellidae); Zetzellia sp. (Stigmaeidae), e espécimes da família Acaridae e da subordem Oribatida não identificadas. Trata-se do primeiro relato da ocorrência da espécie T. confusus em cafeeiro. Da família Tarsonemidae foram encontradas três novas espécies, e da família Iolinidae um novo gênero, para posterior descrição.

Termos para indexação: Coffea arabica, Acari, Tenuipalpidae, Phytoseiidae, Tarsonemidae, Levantamento.

\section{ABSTRACT}

The coffee (Coffea arabica L.) growing in Cerrado areas of Patrocínio, State of Minas Gerais, more specifically in the region of Alto Paranaíba, have been expanding with success. Coffee diseases and pests result in reduction of the productivity and quality. Phytophagous mites are among the pests that cause economic damage. Therefore, this work had as objective the study of the mite fauna on coffee plants in those areas. Four surveys were done, two in the rainy season and two in the drier season of the 2002-2003 period. Three families of phytophagous, four of predaceous and five of "generalists" mites were identified. The mite species were: Brevipalpus phoenicis (Geijskes, 1939) (Tenuipalpidae); Oligonychus sp. (Tetranychidae); Tarsonemus confusus Ewing, 1939, Fungitarsonemus sp., Daidalotarsonemus sp., Phytonemus sp. (Tarsonemidae); Lorrya formosa Cooreman, 1958, Lorrya sp. (Tydeidae), Parapronematus acaciae Baker, 1965 (Iolinidae); Euseius concordis (Chant, 1959), Euseius citrifolius Denmark and Muma, 1970, Amblyseius herbicolus (Chant, 1959) (Phytoseiidae); Asca sp. (Ascidae); Bdella sp. (Bdellidae); Zetzellia sp. (Stigmaeidae), and unidentified specimens of the family Acaridae and of the suborder Oribatida. This is the first report on the occurrence of $T$. confusus in coffee. Also, three new species of Tarsonemidae and a new genus in the family Iolinidae were found, these being kept for later description.

Index terms: Coffea arabica, Tenuipalpidae, Phytoseiidae, Tarsonemidae, Survey.

(Recebido para publicação em $1^{\circ}$ de abril de 2004 e aprovado em 20 de agosto de 2004)

\section{INTRODUÇÃO}

Minas Gerais é o maior produtor de café no Brasil, respondendo com $60 \%$ da produção (ANUÁRIO..., 2001). Muitos estudos sobre a cultura do café são realizados principalmente no Sul de Minas. A região do cerrado mineiro, especialmente a do Alto Paranaíba, vem dominando o mercado cafeeiro. Essa região que antes foi considerada pobre para a agricultura, hoje possui lavouras empresariais, com prioridade para a mecanização e boa qualidade do café produzido. Visto a importância da cultura para a região, estudos fitossanitários são im- prescindíveis, tendo em conta que este é um dos problemas que o cafeicultor enfrenta todos os anos. A incidência de pragas em maior ou menor número, ano após ano prejudica a produtividade e a qualidade do café produzido.

Os ácaros fitófagos estão entre os problemas fitossanitários e são os responsáveis por uma grande parcela dos prejuízos. Existem poucos estudos a respeito dos ácaros que ocorrem em cafeeiros, não apenas no Brasil, mas em todos os países onde essa planta é cultivada (FLECHTMANN, 1967, 1968, 1985).

1. Bióloga Msc. Universidade Federal de Lavras, Departamento de Entomologia - Caixa Postal 3037 - 37.200-000 - Lavras, MG - sheila@esalq.usp.br

2. Engenheiro Agronômo, D.Sc., Pesquisador EPAMIG-CTSM/EcoCentro, bolsista CNPq-Caixa Postal $176-37200-000-$ Lavras, MG paulo.rebelles@epamig.ufla.br

3. Engenheiro Agronômo, D.Sc., Pesq. Embrapa Café - Caixa Postal 176 - 37200-000 - Lavras, MG - zacarias@epamig.ufla.br 
Em cafeeiros, no Brasil, geralmente ocorrem três espécies de ácaros-praga: o ácaro-vermelho Oligonychus ilicis (McGregor, 1917) (Tetranychidae), o ácaro da mancha-anular Brevipalpus phoenicis (Geijskes, 1939) (Tenuipalpidae) (REIS et al., 2000b) e o ácaro-branco Polyphagotarsonemus latus (Banks, 1904) (Tarsonemidae) (REIS e SOUZA, 1986).

Além dos ácaros-praga, o estudo da acarofauna, inclui também a constatação de inimigos naturais, como ácaros predadores pertencentes às famílias Phytoseiidae, Stigamaeidae e Bdellidae (REIS et al., 2000b), entre outras, sendo a família Phytoseiidae a mais conhecida e estudada (McMURTRY e CROFT, 1997). Reis et al. (2000d) demonstraram o potencial de predação que esses ácaros fitoseídeos possuem, principalmente as fêmeas adultas e ninfas sobre B. phoenicis.

Os ácaros que ocorrem em cafeeiros plantados nas regiões cafeicultoras do Estado de São Paulo e Região Sul de Minas Gerais, já estão sendo estudados (PALLINI FILHO, 1991; MINEIRO et al., 2001; SATO et al., 2002), entretanto, faltam estudos para diversas regiões, entre as quais aquelas onde a cafeicultura foi plantada em solo sob vegetação de cerrado como Patrocínio, no Alto Paranaíba, em Minas Gerais. Sendo assim, o objetivo deste trabalho foi o levantamento da acarofauna em cafeeiros (Coffea arabica L.) dessa região.

\section{MATERIAL E MÉTODOS}

As coletas foram feitas em cafeeiros plantados em condições de solo e vegetação do cerrado mineiro, na região do Alto Paranaíba, município de Patrocínio, na Fazenda Experimental de Patrocínio - FEPC da EPAMIG.

Foi utilizada uma área de 60 ha de cultivo de café (Coffea arabica L.) em produção (15 anos) da variedade Catuaí Vermelho sem tratamento fitossanitário, sendo feitas quatro amostragens sendo: 1) Final do período das águas (07/05/02); 2) Meio do período da seca (05/08/02); 3) Final do período da seca $(04 / 11 / 02)$ e 4) Meio do período das águas (04/02/03).

Foram amostrados 10 cafeeiros, tomados aleatoriamente em um talhão de 4 ha, estes foram divididos em 3 setores: terço superior, terço médio e terço inferior. De cada setor foram coletadas 10 folhas, 10 ramos $( \pm 20 \mathrm{~cm}$ da parte apical do ramo) e 20 frutos. Para os frutos a amostragem foi feita somente na primeira e quarta coletas que coincidiram com o período de frutificação.

As amostras foram acondicionadas em sacos de papel individualizando o tipo de material coletado: fo- lhas, ramos e frutos, estes dentro de sacos plásticos transparentes com dados da planta e terço (superior, médio e inferior). Todo o material foi mantido em caixa de isopor com Gelox ${ }^{\circledR}$.

O material, assim acondicionado foi levado até o Laboratório de Acarologia da EPAMIGCTSM/EcoCentro, no Campus da Universidade Federal de Lavras - UFLA, em Lavras/MG, onde foram feitas as coletas dos ácaros pelos métodos de lavagem e varredura a seguir descritos. Os ácaros foram montados em lâminas de microscopia em meio de Hoyer (FLECHTMANN, 1985) para identificação das espécies e avaliação quantitativa.

Os métodos de extração dos ácaros de seus respectivos substratos consistiram em:

Lavagem: folhas e frutos depois de coletados foram acondicionados em sacos plásticos com cobertura total de água com algumas gotas de detergente e agitados vigorosamente. Em seguida o material foi passado por uma peneira de análise de malha de 325 mesh, para reter os ácaros. Os ácaros coletados foram guardados em frascos plásticos com álcool 70\%, para posterior avaliação.

Varredura: apenas os ramos foram avaliados por este método, que consiste na passagem do ramo em um aparelho elétrico, que por meio da rotação de escovas varre todo o material. Os ácaros caem em uma placa de Petri contendo uma fina camada de glicerina mais detergente. Os ácaros assim coletados foram acondicionados em frascos plásticos com álcool 70\%, para posterior avaliação.

Após a lavagem, as folhas foram recortadas próximo a nervura central, preservando as domácias inteiras, e estes recortes foram acondicionados em frascos plásticos contendo álcool 70\% para posterior extração, com o auxílio de um bisturi, dos ácaros que se encontravam dentro das domácias.

\section{RESULTADOS E DISCUSSÃO}

Coletou-se um total de 1299 espécimes de ácaros, distribuídos em 12 famílias sendo três famílias de fitófagos, quatro famílias de predadores, e cinco famílias de generalistas, nas folhas, ramos, frutos e domácias do cafeeiro (Tabelas 1, 2, 3, 4 e 5). A média do número de ácaros em cada coleta nas diferentes partes vegetais do cafeeiro e nos três terços da planta estão apresentadas na Tabela 1. Foram identificados 1085 ácaros, sendo os restantes 214 ácaros machos e imaturos para os quais não foi possível fazer a identificação da espécie. 
Assim como relatado por Mineiro et al. (2001), a maior parte dos ácaros coletados encontravam-se em folhas do terço inferior (Tabela 1 e Figura 1).

Dentre todos os ácaros coletados, as espécies que mais se destacaram numericamente foram $B$. phoenicis e Tarsonemus confusus Ewing, 1939 (Tarsonemidae).

Foram coletados 855 espécimes de ácaros pertencentes à família Tenuipalpidae, representando cerca de $65 \%$ do total coletado, sendo 604 da espécie $B$. phoenicis. Pallini Filho (1991) e Sato et al. (2002) encontraram resultados semelhantes em levantamento feito em cafeeiros em Lavras e Machado/MG, e Garça/SP, respectivamente. Do total de Tenuipalpidae coletado, aproximadamente $30 \%$ eram imaturos e não puderam ser identificados, mas provavelmente, são da espécie $B$. phoenicis, pois foi a única encontrada em todas as coletas nos cafeeiros.

Reis et al. (2000c) e Mineiro et al. (2001) constataram que B. phoenicis ocorreu em maior quantidade nas folhas, ramos e frutos do terço inferior, porém, o mesmo não ocorreu neste levantamento, onde apenas nas folhas $B$. phoenicis foi registrado em maior quantidade no terço inferior, que representou $47 \%$ dos ácaros dessa espécie encontrados. Nos ramos, assim como nos frutos, o terço superior foi o local de maior ocorrência de B. phoenicis (Tabelas 2, 3, 4 e 5). Em domácias foram coletados 72 ácaros, sendo que $70 \%$ destes eram imaturos pertencentes à família Tenuipalpidae, possivelmente B. phoenicis.

O ácaro B.phoenicis foi encontrado durante todo o período de estudo. Populações menores foram obser- vadas no período do meio da seca (agosto/2002) (99 ácaros) e o maior número foi registrado no final da seca (novembro/2002) (309 ácaros), representando 36\% dos espécimes de $B$. phoenicis coletados.

Oligonychus sp. foi encontrado em baixos níveis populacionais, representando apenas cerca de $4 \%$ de todos os ácaros coletados. A identificação da espécie não foi possível devido à ausência de machos nas coletas, os quais apresentam as características que permitem a identificação da espécie. O baixo número de ácaros coletados deste gênero deve-se a uma não coincidência de sua ocorrência, ou maiores populações, com as coletas. A espécie mais comum do gênero Oligonychus em cafeeiro é O. ilicis que está associada a períodos de seca e utilização excessiva de alguns produtos fitossanitários (REIS e TEODORO, 2000).

Neste estudo, foram também encontrados ácaros pertencentes à família Phytoseiidae, Stigmaeidae, Bdellidae e Ascidae. Esses ácaros são tipicamente predadores (McMURTRY et al., 1970; HELLE e SABELIS, 1985; GERSON e SMILEY, 1990).

A família Phytoseiidae se destacou com o maior número de espécimes predadores coletados (82 ácaros), sendo que a maioria encontrava-se em folhas do terço inferior (37\%). Euseius citrifolius Denmark e Muma, 1970 foi à espécie mais freqüente com aproximadamente $43 \%$ de ocorrência entre os fitoseídeos. Amblyseius herbicolus (Chant, 1959) e E. concordis (Chant, 1959), foram as outras duas espécies de fitoseídeos encontrados (Tabelas 2, 3, 4 e 5).

TABELA 1 - Número médio de ácaros ( \pm erro padrão da média, entre parêntesis) coletados nas diferentes partes vegetativas do cafeeiro e nos terços superior, médio e inferior da planta. Patrocínio, Minas Gerais, 2002-2003.

\begin{tabular}{cccccccccccccc}
\hline \multirow{2}{*}{ Amostra } & \multicolumn{3}{c}{ Maio 2002 } & \multicolumn{4}{c}{ Agosto 2002 } & \multicolumn{3}{c}{ Novembro 2002 } & \multicolumn{3}{c}{ Fevereiro 2003 } \\
\cline { 2 - 13 } & TS & TM & TI & TS & TM & TI & TS & TM & TI & TS & TM & TI \\
\hline \multirow{2}{*}{ Folhas } & 3,00 & 10,40 & 13,60 & 0,60 & 1,60 & 4,60 & 1,40 & 7,30 & 13,90 & 3,80 & 6,70 & 7,40 \\
& $(0,73)$ & $(3,02)$ & $(5,27)$ & $(0,49)$ & $(0,83)$ & $(0,73)$ & $(0,90)$ & $(3,31)$ & $(3,59)$ & $(1,04)$ & $(1,84)$ & $(2,14)$ \\
Ramos & 4,40 & 2,00 & 1,00 & 0,60 & 1,00 & 0,20 & 1,52 & 1,20 & 0,60 & 3,10 & 4,10 & 5,10 \\
& $(1,59)$ & $(0,47)$ & $(0,42)$ & $(1,26)$ & $(0,49)$ & $(0,20)$ & $(0,77)$ & $(0,38)$ & $(0,26)$ & $(1,06)$ & $(1,17)$ & $(2,01)$ \\
Domácias & 1,10 & 0,40 & 0 & 0,20 & 0,10 & 0,30 & 0 & 0 & 0 & 0,20 & 0 & 0 \\
& $(0,69)$ & $(0,26)$ & & $(0,20)$ & $(0,10)$ & $(0,30)$ & & & & $(0,13)$ & & \\
Frutos & 1,00 & 0 & 0 & 0 & - & - & - & - & - & 1,70 & 2,40 & 1,50 \\
& $(0,68)$ & & & & & & & & & $(0,57)$ & $(0,65)$ & $(0,67)$ \\
\hline
\end{tabular}

TS-Terço Superior; TM-Terço Médio; TI-Terço Inferior.

Ciênc. agrotec., Lavras, v. 29, n. 1, p. 9-17, jan./fev. 2005 
TABELA 2 - Espécies e número de ácaros coletados nas diferentes partes vegetais de cafeeiros. Patrocínio, Minas Gerais, primeira coleta em Maio/2002 (final do período das águas).

\begin{tabular}{|c|c|c|c|c|c|c|c|c|c|c|c|c|c|}
\hline \multirow{3}{*}{ Famílias/Espécies } & \multicolumn{13}{|c|}{ Número de ácaros/partes do cafeeiro/altura } \\
\hline & \multicolumn{3}{|c|}{ Folhas } & \multicolumn{3}{|c|}{ Ramos } & \multicolumn{3}{|c|}{ Frutos } & \multicolumn{3}{|c|}{ Domácias } & \multirow[t]{2}{*}{ Total } \\
\hline & TS & TM & TI & TS & $\mathbf{T M}$ & TI & TS & $\mathbf{T M}$ & TI & & TM & & \\
\hline Tenuipalpidae & & & & & & & & & & & & & \\
\hline Brevipalpus phoenicis & 07 & 74 & 96 & 08 & 05 & 02 & 10 & & & & & & 202 \\
\hline Tetranychidae & & & & & & & & & & & & & \\
\hline Oligonychus sp. & 09 & 06 & 09 & & & & & & & & & & 24 \\
\hline Tarsonemidae & & & & & & & & & & & & & \\
\hline Fungitarsonemus sp. & 04 & 11 & 13 & 01 & & & & & & & & & 29 \\
\hline Tarsonemus confusus & & & & 10 & & & & & & & & & 10 \\
\hline \multicolumn{14}{|l|}{ Phytoseiidae } \\
\hline Euseius citrifolius & 04 & 01 & 02 & & & & & & & & & & 7 \\
\hline Euseius concordis & 05 & 03 & 0 & & & & & & & & & & 8 \\
\hline Amblyseius herbicolus & & 03 & 13 & & & & & & & & & & 16 \\
\hline Ascidae & & & & & & & & & & & & & \\
\hline Asca sp. & & & & 02 & 02 & & & & & & & & 4 \\
\hline \multicolumn{14}{|l|}{ Bdellidae } \\
\hline Bdella sp. & & & 01 & & & & & & & & & & 1 \\
\hline \multicolumn{14}{|l|}{ Tydeidae } \\
\hline Lorrya formosa & & & & & & & & & & & 02 & & 2 \\
\hline Lorrya sp. & & & 01 & & & & & & & 10 & & & 11 \\
\hline \multicolumn{14}{|l|}{ Iolinidae } \\
\hline Iolinidae sp.1 & & & & & & & & & & 01 & 02 & & 3 \\
\hline Acaridae & & & 01 & 05 & 02 & & & & & & & & 8 \\
\hline Oribatida & 01 & 06 & & 18 & 11 & 08 & & & & & & & 44 \\
\hline Total & 30 & 104 & 136 & 44 & 20 & 10 & 10 & 0 & 0 & 11 & 04 & 0 & 0 \\
\hline Total Geral & & 270 & & & 74 & & & 10 & & & 15 & & \\
\hline
\end{tabular}

TS - Terço Superior; TM - Terço Médio; TI - Terço Inferior. 
TABELA 3 - Espécies e número de ácaros coletados nas diferentes partes vegetais de cafeeiros. Patrocínio, Minas Gerais, segunda coleta em Agosto/2002 (meio do período da seca).

\begin{tabular}{|c|c|c|c|c|c|c|c|c|c|c|c|c|c|}
\hline \multirow{3}{*}{ Famílias/Espécies } & \multicolumn{13}{|c|}{ Número de ácaros/partes do cafeeiro/altura } \\
\hline & \multicolumn{3}{|c|}{ Folhas } & \multicolumn{3}{|c|}{ Ramos } & \multicolumn{3}{|c|}{ Frutos } & \multicolumn{3}{|c|}{ Domácias } & \multirow{2}{*}{ Total } \\
\hline & TS & $\mathbf{T M}$ & TI & $\mathbf{T S}$ & $\mathbf{T M}$ & TI & TS & TM & TI & TS & TM & TI & \\
\hline \multicolumn{14}{|l|}{ Tenuipalpidae } \\
\hline Brevipalpus phoenicis & 03 & 11 & 32 & 01 & 07 & 02 & - & - & - & & & & 56 \\
\hline \multicolumn{14}{|l|}{ Tarsonemidae } \\
\hline Fungitarsonemus sp. & 02 & 01 & 03 & & & & - & - & - & & & & 06 \\
\hline Tarsonemus confusus & & 01 & 01 & & 02 & & - & - & - & 01 & & & 05 \\
\hline \multicolumn{14}{|l|}{ Stigmaeidae } \\
\hline Zetzellia sp. & & & & & & & - & - & - & 01 & & & 01 \\
\hline \multicolumn{14}{|l|}{ Tydeidae } \\
\hline Lorrya sp. & & & & 02 & 01 & & - & - & - & & 01 & 03 & 07 \\
\hline \multicolumn{14}{|l|}{ Iolinidae } \\
\hline Parapronematus acaciae & & 03 & 08 & & & & & & & & & & 11 \\
\hline Acaridae & 01 & & & & & & & & & & & & 01 \\
\hline Oribatida & & & 02 & 03 & & & & & & & & & 05 \\
\hline Total & 06 & 16 & 46 & 06 & 10 & 02 & - & - & - & 02 & 01 & 03 & \multirow{2}{*}{92} \\
\hline Total Geral & & 68 & & & 18 & & & - & & & 06 & & \\
\hline
\end{tabular}

TS - Terço Superior; TM - Terço Médio; TI - Terço Inferior

TABELA 4- Espécies e número de ácaros coletados nas diferentes partes vegetais de cafeeiros. Patrocínio, Minas Gerais, terceira coleta em Novembro/2002 (final do período da seca).

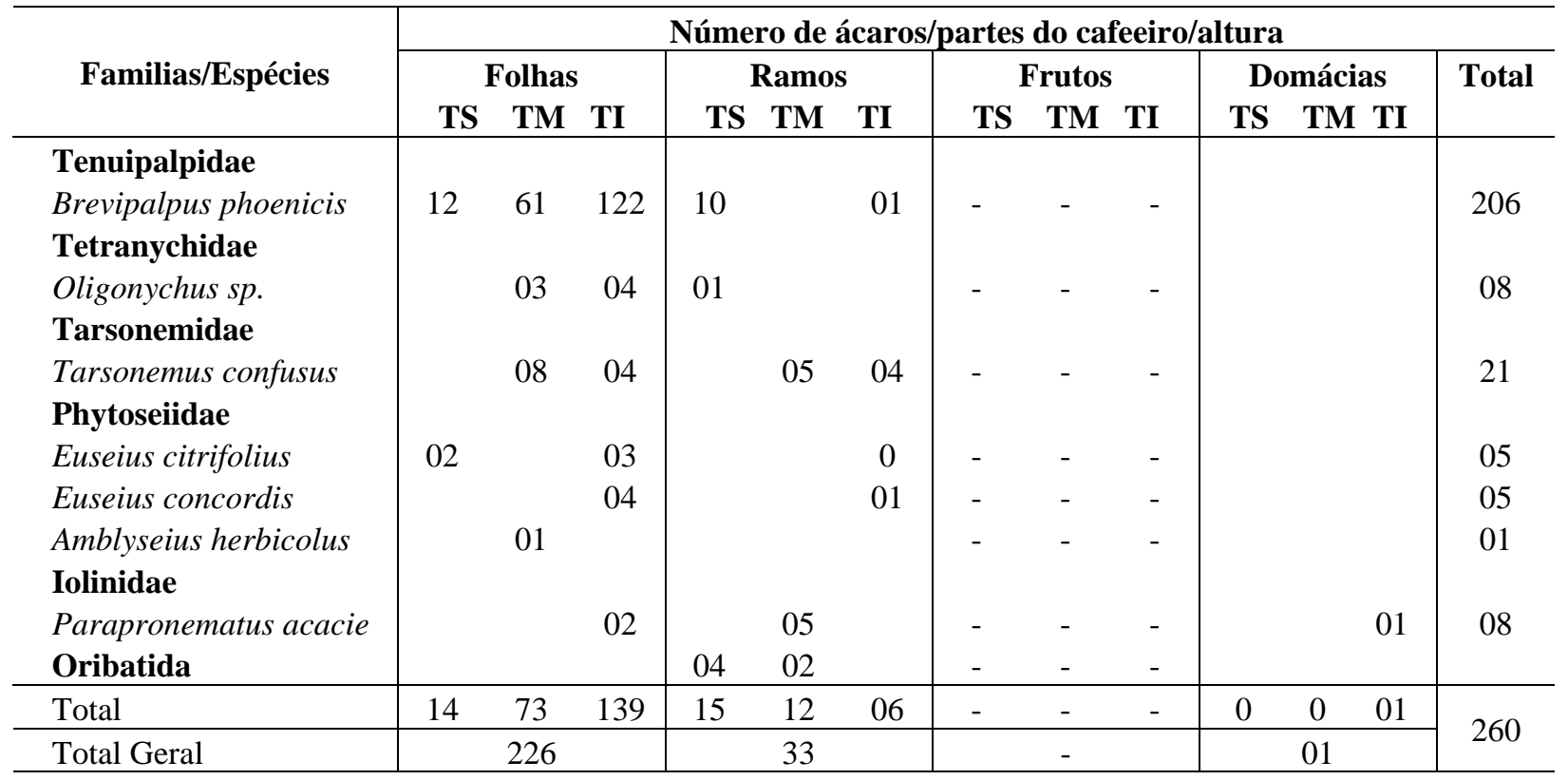

TS - Terço Superior; TM - Terço Médio; TI - Terço Inferior 
TABELA 5- Espécies e número de ácaros coletados nas diferentes partes vegetais de cafeeiros. Patrocínio, Minas Gerais, quarta coleta em Fevereiro/2003 (meio do período das águas).

\begin{tabular}{|c|c|c|c|c|c|c|c|c|c|c|c|c|c|}
\hline \multirow{3}{*}{ Familias/Espécies } & \multicolumn{13}{|c|}{ Número de ácaros/partes do cafeeiro/altura } \\
\hline & \multicolumn{3}{|c|}{ Folhas } & \multicolumn{3}{|c|}{ Ramos } & \multicolumn{3}{|c|}{ Frutos } & \multicolumn{3}{|c|}{ Domácias } & \multirow{2}{*}{ Total } \\
\hline & TS & TM & TI & TS & TM & $\mathbf{T I}$ & TS & TM & TI & TS & TM & TI & \\
\hline \multicolumn{14}{|l|}{ Tenuipalpidae } \\
\hline Brevipalpus phoenicis & 13 & 20 & 37 & 10 & 05 & 09 & 13 & 18 & 15 & & & & 140 \\
\hline Tetranychidae & & & & & & & & & & & & & \\
\hline $\begin{array}{l}\text { Oligonychus sp. } \\
\text { Tarsonemidae }\end{array}$ & 01 & 02 & 04 & 01 & & 01 & & & & & & & 09 \\
\hline Tarsonemus confusus & 12 & 31 & 19 & 13 & 34 & 23 & 04 & 06 & & & & & 142 \\
\hline Tarsonemus sp.1 & 02 & & & & 05 & 06 & & & & & & & 13 \\
\hline Tarsonemus sp.2 & & & 02 & & & & & & & & & & 02 \\
\hline Tarsonemus sp.3 & & & 01 & & & & & & & & & & 01 \\
\hline Daidalotarsonemus sp. & & & & 01 & & 01 & & & & & & & 02 \\
\hline Phytonemus sp. & & & & & & 03 & & & & & & & 03 \\
\hline \multicolumn{14}{|l|}{ Phytoseiidae } \\
\hline Euseius citrifolius & 07 & 12 & 06 & 01 & 01 & & & & & 02 & & & 29 \\
\hline Euseius concordis & 02 & 02 & 04 & & & & & & & & & & 08 \\
\hline Amblyseius herbicolus & & 01 & 0 & & 02 & 03 & & & & & & & 06 \\
\hline Stigmaeidae & & & & & & & & & & & & & \\
\hline Zetzellia sp. & & 01 & 01 & 01 & & & & & & & & & 03 \\
\hline Bdellidae & & & & & & & & & & & & & \\
\hline Bdella sp. & 01 & & & & & & & & & & & & 01 \\
\hline Ascidae & & & & & & & & & & & & & \\
\hline Asca sp. & & & & & 02 & 03 & & & & & & & 05 \\
\hline Total & 38 & 69 & 74 & 27 & 49 & 49 & 17 & 24 & 15 & 02 & 0 & 0 & 364 \\
\hline Total Geral & & 181 & & & 125 & & & 56 & & & 02 & & 307 \\
\hline
\end{tabular}

TS - terço Superior; TM - Terço Médio; TI - Terço Inferior 
Primeira Coleta $-05 / 2002$

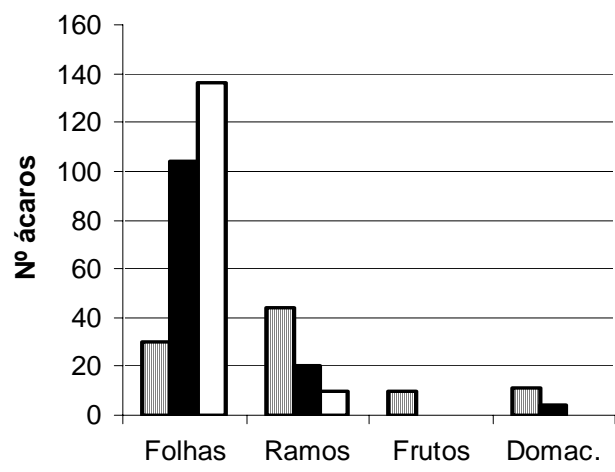

Terceira Coleta $-11 / 2002$

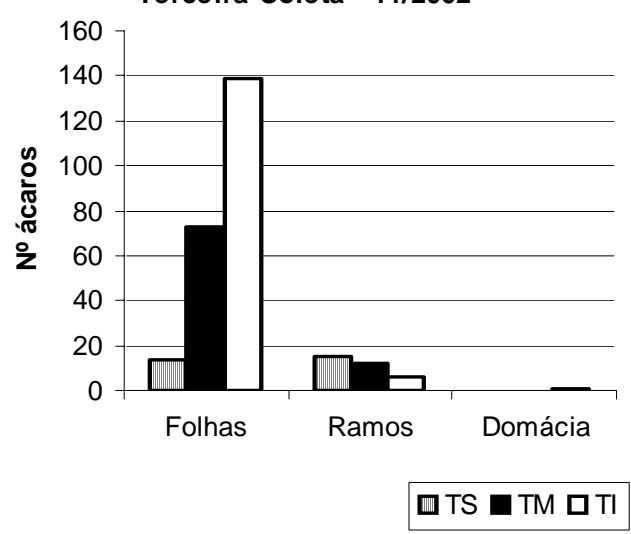

Segunda Coleta $-08 / 2002$

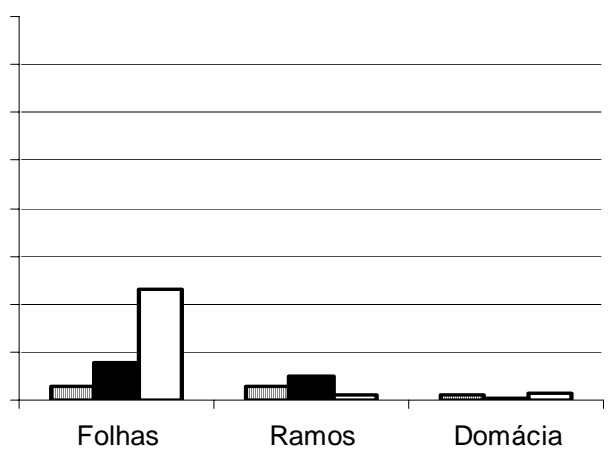

Quarta Coleta - 02/2003

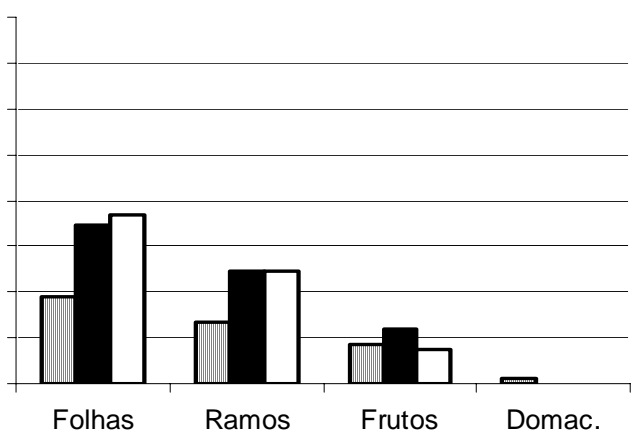

FIGURA 1 - Número total de ácaros coletados nas diferentes partes vegetais do cafeeiro durante o período de estudo em Patrocínio, MG, 2002-2003.

A presença de Iphiseiodes zuluagai Denmark e Muma, 1972 em cafeeiros tem sido relatada por autores em várias localidades (PALLINI FILHO, 1991; REIS et al., 2000b; MINEIRO et al., 2001), contudo essa espécie não foi coletada no presente estudo. Sato et al. (2002), também não registraram a presença dessa espécie em Garça/SP. Pallini Filho (1991) relacionou a ocorrência de I. zuluagai em cafeeiros no Sul de Minas Gerais à baixa precipitação e temperaturas amenas, o mesmo foi relatado em citros (Citrus sinensis, Osbeck) por Sato et al. (1994), em São Paulo e por Reis et al. (2000a) também em citros (C. sinensis), em Lavras, Sul de Minas Gerais. Sendo assim, o clima desfavorável pode ser um dos fatores da não constatação deste fitoseídeo na região de cerrado em Patrocínio/MG. Nove espécimes da família Ascidae foram encontrados em ramos.

A segunda espécie encontrada em maior quantidade numérica foi $T$. confusus. Foram coletados 180 espécimes, representando cerca de $13 \%$ do total de ácaros. Esse ácaro também esteve presente em todas as partes das plantas amostradas e em todas as coletas. Nas folhas, o terço médio foi o local de maior incidência, representando cerca de $47 \%$ dos ácaros encontrados. Nos 
ramos, assim como nas folhas houve predominância desta espécie também no terço médio (Tabelas 2, 3, 4 e 5). T. confusus apresenta ampla distribuição geográfica, havendo relatos na América do Norte (EUA e Canadá), Europa (Turquia, Itália, Irlanda, Alemanha, Polônia, Ucrânia e Rússia), Ásia (Japão, Coréia, China) e África (Egito). Pode ser encontrado em muitas espécies de plantas, no solo, na poeira domiciliar e ninhos de pássaros. T. confusus foi primeiramente relatado como sendo fungívoro, porém, existem outros relatos da ocorrência desse ácaro causando danos em plantas ornamentais em casa-de-vegetação na Europa, e na cultura do tomate na América do Norte (ZHANG, 2003). Na Bélgica causa danos na cultura da azaléia, como citado por Heungens e Tirry (2000). Na China, Wang et al. (1999) descreveram danos causados em pessegueiro. Até o presente estudo, essa espécie de ácaro ainda não havia sido relatada em cafeeiros. Além de T. confusus outro tarsonemideo, Fungitarsonemus sp. foi coletado na primeira e segunda coleta em um total de 35 espécimes. Foram também encontradas três novas espécies do gênero Tarsonemus, ainda não descritas.

O ácaro T. confusus ocorreu durante todo o período de estudo, sendo que nas três primeiras coletas (maio/02; agosto/02 e novembro/02) foram registrados em pequeno número, entretanto, na quarta coleta (fevereiro/03) foi notado um pico populacional representando $79 \%$ da sua ocorrência, fato que pode ser devido à alta umidade relativa e precipitação pluvial do período. Contudo, outros estudos sobre a flutuação populacional desta espécie de ácaro devem ser feitos para que essas e outras dúvidas sejam esclarecidas. Além disso, a biologia de T. confusus sobre cafeeiros deve ser estudada com a finalidade de se descobrir seus hábitos, principalmente de alimentação, pois $T$. confusus pode ser fitófago e estar causando danos ao cafeeiro, ou pode estar se alimentando de fungos, como a ferrugem-do-cafeeiro, Hemileia vastatrix (Berk e Br.) ou de outros fungos.

\section{CONCLUSÕES}

As seguintes espécies de ácaros estão comumente associadas ao cafeeiro (C. arabica) na região de cerrado em Patrocínio, Minas Gerais: Fitófagos: Brevipalpus phoenicis (Geijskes, 1939) (Tenuipalpidae) e Oligonychus sp. (Tetranychidae). Predadores: Euseius concordis (Chant, 1959), Euseius citrifolius Denmark e Muma, 1970 e Amblyseius herbicolus (Chant, 1959) (Phytoseiidae); Zetzellia sp. (Stigmaeidae); Bdella sp. (Bdellidae) e Asca sp. (Ascidae). Generalistas: Tarsonemus confusus Ewing, 1939, Phytonemus sp., Fungitarsonemus sp., Daidalotarsonemus sp., Tarsonemus sp.1, sp.2 e sp.3 (Tarsonemidae); Lorrya formosa Cooreman, 1958, Lorrya sp. (Tydeidae); Parapronematus acaciae Baker, 1965 (Iolinidae), Iolinidae sp.1 (Iolinidae); espécies da família Acaridae e da subordem Oribatida não identificados.

O meio do período da seca é a época mais desfavorável a todas as espécies de ácaros que ocorrem na cafeicultura de cerrado.

Devido à existência de espécies de ácaros ainda não referidas e também não descritas em cafeeiro, há necessidade de mais estudos para aprofundamento do conhecimento taxonômico da acarofauna da cafeicultura nas diversas regiões produtoras.

\section{REFERÊNCIAS BIBLIOGRÁFICAS}

ANUÁRIO estatístico do café. Rio de Janeiro: Coffee Business, 2001. $161 \mathrm{p}$.

FLECHTMANN, C. H. W. Os ácaros do cafeeiro. Anais da Escola Superior de Agricultura "Luis de Queiroz”, Piracicaba, v. 24, p. 91-95, 1967.

FLECHTMANN, C. H. W. Ácaros do cacaueiro, cafeeiro e do chá. Piracicaba: ESALQ-USP, 1968. 11 p. (Boletim de Divulgação, 6).

FLECHTMANN, C. H. W. Ácaros de importância agrícola. São Paulo: Nobel, 1985. 189 p.

GERSON, U.; SMILEY, R. L. Acarine biocontrol agents: an illustrated key and manual. Londres: Chapman and Hall, 1990. 174 p.

HELLE, W.; SABELIS, M. W. (Eds.). Spider mites: their biology, natural enemies and control. Amsterdam: Elsevier, 1985. v. 1A, v. 1B.

HEUNGENS, A.; TIRRY, L. Curative chemical control of the tarsonemid mites Tarsonemus confusus and Tarsonemoides belemnitoides in azalea culture. Parasitica, Bruxelles, v. 56, n. 4, p. 123-130, 2000.

McMURTRY, J. A.; CROFT, B. A. Life-styles of phytoseiid mites and their roles in biological control. Annual Review of Entomology, Berkeley, v. 42, p. 291-321, 1997. 
McMURTRY, J. A.; HUFFAKER, C. B.; VRIE, M. van de. Ecology of Tetranychidae mites and their natural enemies: a revision. Hilgardia, Berkeley, v. 40, n. 11, p. 331-90, Dec. 1970.

MINEIRO, J. L. de C. et al. Distribuição da acarofauna em cafeeiro (Coffea arabica var. Catuaí amarelo), em Atibaia, SP. In: SIMPÓSIO BRASILEIRO DE PESQUISA DOS CAFÉS DO BRASIL, 2., 2001, Vitória, ES. Resumos... Brasília: Embrapa Café, 2001. p. 132.

PALLINI FILHO, A. Acarofauna e predação de ácaros fitófagos por ácaros predadores em cafeeiro (Coffea arabica L.) no sul de Minas Gerais. 1991. 91 p. Dissertação (Mestrado em Entomologia) - Universidade Federal de Lavras, Lavras, 1991.

REIS, P. R. et al. Ácaros da família Phytoseiidae associados aos citros no Município de Lavras, Sul de Minas Gerais. Anais Sociedade Entomológica do Brasil, Itabuna, v. 29, n. 1, p. 95-104, mar. 2000a.

REIS, P. R. et al. Flutuação populacional do ácaro da mancha-anular do cafeeiro e seus inimigos naturais. In: SIMPÓSIO DE PESQUISA DOS CAFÉS DO BRASIL, 2000, Poços de Caldas. Resumos expandidos... Brasília: EMBRAPA-CAFÉ, 2000b. v. 2, p. 1210-1212.

REIS, P. R. et al. Distribuição espacial do ácaro Brevipalpus phoenicis (Geijskes) (Acari: Tenuipalpidae) em cafeeiro (Coffea arabica L.). Anais da Sociedade Entomológica do Brasil, Itabuna, v. 29, n. 1, p. 177183, 2000c.
REIS, P. R.; SOUZA, J. C. de. Pragas do cafeeiro. In: RENA, A. B. et al. (Eds.). Cultura do cafeeiro: fatores que afetam a produtividade. Piracicaba: POTAFOS, 1986. p. 323-378.

REIS, P. R.; TEODORO, A. V. Efeito de oxicloreto de cobre sobre a reprodução do ácaro-vermelho-docafeeiro, Oligonychus ilicis (McGregor, 1917). Ciência e Agrotecnologia, Lavras, v. 24, n. 2, p. 347-352, abr./jun. 2000.

REIS, P. R.; TEODORO, A. V.; PEDRO NETO, M. Predatory activity of phytoseiid mites on the development stages of coffee ringspot mite (Acari: Phytoseiidae, Tenuipalpidae). Anais da Sociedade Entomológica do Brasil, Itabuna, v. 29, n. 3, p. 547-553, set. 2000d.

SATO, M. E. et al. Ácaros fitófagos e predadores em diferentes cultivares de Coffea spp., em Garça, SP. In: CONGRESSO BRASILEIRO DE PESQUISAS CAFEEIRAS, 2000, Caxambu, MG. Trabalhos apresentados... Rio de Janeiro: MAPA/PROCAFÉ, 2002. p. 283-284.

SATO, M. E. et al. Ácaros predadores em pomar cítrico de Presidente Prudente, Estado de São Paulo. Anais da Sociedade Entomológica do Brasil, Itabuna, v. 23, n. 3, p. 435-441, dez. 1994.

WANG, H. et al. Two new mite species discovered on peach trees. China Fruits, China, v. 55, n. 2, 1999.

ZHANG, Z. Q. Mites of greenhouses: identification, biology and control. Oxon: CAB, 2003. 244 p. 